\title{
Telecommuting and Gender Inequalities in Parents' Paid and Unpaid Work Before and During the COVID-19 Pandemic
}

\begin{abstract}
Objective: This study examines the relationship between telecommuting and gender inequalities in parents' time use at home and on the job before and during the COVID-19 pandemic.

Background: Telecommuting is a potential strategy for addressing the competing demands of work and home and the gendered ways in which they play out. Limited evidence is mixed, however, on the implications of telecommuting for mothers' and fathers' time in paid and unpaid work. The massive increase in telecommuting due to COVID-19 underscores the critical need to address this gap in the literature.
\end{abstract}

Method: Data from the 2003-2018 American Time Use Survey (ATUS, $N=12,519$ ) and the 2020 Current Population Survey $(N=83,676)$ were used to estimate the relationship between telecommuting and gender gaps in parents' time in paid and unpaid work before and during the pandemic. Matching and quasi-experimental methods better approximate causal relationships than prior studies.

Results: Before the pandemic, telecommuting was associated with larger gender gaps in housework and work disruptions but smaller gender gaps in childcare, particularly among couples with two full-time earners. During the pandemic, telecommuting mothers maintained paid work to a greater extent than mothers working on-site, whereas fathers' work hours did not differ by work location.

Conclusion: In the context of weak institutional support for parenting, telecommuting may offer mothers a mechanism for remaining attached to the labor market and reduce gender gaps in childcare, while exacerbating inequalities in housework and disruptions to paid work. 


\section{INTRODUCTION}

The global pandemic has led to an unprecedented shift to remote work. Prior to the COVID-19 crisis, $16 \%$ of U.S. workers reported working some time from home on an average day (Kim et al. 2020, U.S. Bureau of Labor Statistics 2019). Data collected by the U.S. Census Bureau in August through December of 2020 showed that more than a third of all householdsand the vast majority of high-income households - reported working from home more frequently during the pandemic than before (Marshall et al. 2021). Based on a national study from the Pew Research Center, most employees working from home in October of 2020 said they would like to continue to do so after the pandemic, and women were more likely than men to say they would be interested in exclusively working from home (Parker et al. 2020). Telecommuting prior to the pandemic was limited by employers' reluctance to give up direct supervisory control and concerns that the loss of face time would constrain the productive process (Allen et al. 2015, Miller and Rampell 2013). COVID-19 has changed this in the short term and will likely lead to long-run restructuring and a higher baseline share working from home (Bloom et al. 2020, Eavis and Haag 2021). The rise of telecommuting raises questions at the intersection of work and home life that are critical for research and policy.

Telecommuting and other work arrangements that provide control over the location or timing of work have been offered as a strategy for addressing the competing demands of work and home - and the inequalities that stem from gendered time commitments (e.g. Goldin 2014, Ishizuka and Musick 2021, Gajendran and Harrison 2007). U.S. workers cite flexibility and control over their schedules as desirable features of work (Brenan 2020, Mas and Pallais 2017), and women with children in particular are willing to take wage penalties in exchange for more flexibility in work hours and locations (Mas and Pallais 2017). This is in the context of a 
relatively punishing labor market in terms of hours and inflexibility, with little of the institutional support in place elsewhere to mitigate work-family conflict (Gornick and Meyers 2003, Pettit and Hook 2009). For mothers, inflexible workplace demands are intensified by enduring gendered expectations of caretaking and housework (Blair-Loy 2003, Townsend 2002). Mothers carry a disproportionate share of the work at home, and this is reflected in their weaker labor force attachment and earnings relative to fathers (Kühhirt 2012, Musick et al. 2020). Evidence on the effectiveness of telecommuting as a mechanism for addressing inequality between mothers and fathers is mixed (for a review, see Allen et al. 2015, see also Glass and Noonan 2016, Noonan and Glass 2012, Noonan et al. 2007, Weeden 2005, Russell et al. 2009).

Various factors complicate our understanding of the link between telecommuting and the gender division of labor at home and work. First, not all telecommuting arrangements increase work flexibility. Taking work home from a day at the office, for example, is a form of telecommuting that extends the work day and yields lower wages relative to on-site work (Glass and Noonan 2016). Second, the blurrier boundaries between work and home associated with telecommuting may alleviate tension between the two but also interact with gendered expectations of caretaking and housework and leave mothers more vulnerable to work disruptions and multitasking while working at home (Offer and Schneider 2011, Yavorsky et al. 2021). Finally, estimated effects of telecommuting may be confounded by selection into working from home, both among those seeking greater flexibility for domestic responsibilities and those offered work from home as a reward for high performance (Glass and Noonan 2016, Weeden 2005). These selection processes no doubt shifted during the pandemic, as did many other features of working from home in the context of COVID-19. Parents have had less choice in their work arrangements and less institutional and informal support for childcare and schooling 
during the pandemic (Petts et al. 2021, Yavorsky et al. 2021, Collins et al. 2021), and they have experienced much greater difficulty working from home without interruption than men and women without children (Marshall et al. 2021). At a time of heightened demands at home, telecommuting may nonetheless have offered more flexibility to manage work and family relative to on-site work. A better understanding of parents' telecommuting before and during the pandemic addresses its potential to ease work-family conflict in a post-pandemic labor market in which work from home is more fully incorporated.

This paper examines the relationship between parents' telecommuting and gendered time commitments to paid and unpaid work. Our main analysis uses two samples of nationally representative time diary data from the American Time Use Survey (ATUS; https://www.bls.gov/tus/) to estimate the effects of mothers' and fathers' telecommuting on gender gaps in paid work and household labor before the COVID-19 pandemic. Our supplementary set uses new questions from the monthly Current Population Survey (CPS; https://www.bls.gov/covid19/measuring-the-effects-of-the-coronavirus-covid-19-pandemicusing-the-current-population-survey.htm) collected in May to November 2020 to estimate the link between parents' telecommuting and gender gaps in work hours and family-related part-time work during the pandemic. These analyses advance our understanding of telecommuting in three key ways. First, we use innovative methods, including matching and a natural experimental approach, to account for selection into telecommuting and provide leverage in estimating the causal effect of telecommuting on gendered time use. Second, we rely on time diaries to generate finer-grained and more reliable estimates of telecommuting than much past work (Robinson 2002), including measures of work fragmentation and the co-presence of children to tap the quality of work time, and attention to the mix of diary day work at home and the workplace to 
tap different forms of telecommuting. Finally, this paper provides some of the first estimates of gendered time use by telecommuting status during the pandemic. Broadly, our work responds to calls for predicting and understanding the impact of COVID-19 on gender equality (Alon et al. 2020).

\section{BACKGROUND}

\section{Mechanisms Linking Telecommuting and Parents' Time Use in Paid and Unpaid Work}

Although the issues are not new, telecommuting during the pandemic has highlighted the importance of understanding how working from home shapes parents' time in paid and unpaid work. Work arrangements that provide greater control over the location or timing of work have long been put forward as a potential fix for the work-family conflict that disparately impacts mothers, who continue to do far more care work and housework than fathers (Bianchi et al. 2012, Sayer et al. 2004). To the extent that telecommuting offers greater work hour flexibility, it may make it possible for some mothers to stay in jobs who would otherwise drop out (Goldin 2014, Ishizuka and Musick 2021). Like other policies and practices that address work-family conflict, however, telecommuting may have different implications for women and men that ultimately exacerbate some dimensions of inequality (Gornick and Meyers 2003, Pettit and Hook 2009). In the case of telecommuting, these may include inequalities in housework and childcare and the quality of work time.

Gendered social norms that underpin the domestic division of labor may differentially shape the effects of flexible work practices like telecommuting. Gendered norms continue to tie fatherhood primarily to full-time employment and motherhood to time-intensive, child-centered caregiving (Blair-Loy 2003, Townsend 2002). One way these play out is in the greater responsiveness of women's time use and labor market attachment to household circumstances 
such as caregiving needs and spouse work hours (Bianchi 2000, Musick and Jeong 2021).

Because telecommuting removes the distance between work and home provided by traditional workplaces, it potentially allows more give in managing the competing demands of work and family. Combined with the stronger expectations of childcare and housework, mothers' increased availability working from home may be tapped more often than fathers' for children's needs or housework.

The gendered division of household activities may further exacerbate this dynamic, particularly for housework. Women do more routine, time-sensitive tasks such as cooking and cleaning ("female-typed tasks"), whereas men do more infrequent household tasks such as home and vehicle repairs ("male-typed tasks"), which allow more flexibility in scheduling and do not typically disrupt paid work (Noonan 2001). The exigencies of female-typed housework suggest that telecommuting mothers may disproportionately turn their time to domestic tasks. Mothers are similarly more likely to "cover the goal" in childcare tasks, ensuring needs are met and emergencies attended to, whereas fathers engage in more discretionary activities and outings (Musick et al. 2016, Bianchi 2000). Nonetheless, evidence suggests that processes shaping mothers' and fathers' time in childcare are different from those shaping time in housework (Kroska 2003, Sullivan 2013). Fathers' time in childcare has changed in more meaningful ways than in housework, and increased time availability (measured by work hours) is associated with longer housework hours among mothers than fathers, but comparable increases in childcare hours (Chesley and Flood 2017). Any increase in parents' availability associated with telecommuting may thus disproportionately increase mothers' housework but lead to more similar increases in mothers' and fathers' childcare time. 
Beyond telecommuting's effect on the amount of time spent in paid and unpaid work, the blurrier boundary between work and home and the greater responsiveness of women to family demands may have disparate impacts on the quality of the work environment at home. Mothers spend more time multitasking than fathers, and the additional hours are mainly on housework and childcare (Offer and Schneider 2011). To the extent that mothers working from home are simultaneously on task to manage children or other household demands, their telecommuting time may be more affected than fathers' by disruptions to work that divide their attention between work and family. We see evidence of this in other domains of time use, with mothers' leisure more often spent in the presence of children and more often interrupted by housework and childcare (Craig and Mullan 2013, Mattingly and Blanchi 2003). Gender gaps in interruptions and multitasking may extend to telecommuting time, with potential implications for career advancement and pay.

The mechanisms linking telecommuting and parents' time use in paid and unpaid work may vary across family types in ways that shape their gendered associations. In particular, there may be fewer assumptions about the default caretaking role of mothers in families with two fulltime earners. Compared to couples with a male breadwinner, those with two full-time working parents tend to have more egalitarian gender beliefs (Torr and Short 2004), smaller housework gaps (Hook 2010, Craig 2007), and a more equal division of childcare (Craig and Mullan 2011). Parents in full-time, dual-earning families report greater time pressure than those in families with a part-time or nonworking spouse (Bianchi and Wight 2011). Mothers and fathers in these family situations may use their telecommuting time more similarly, with smaller gendered implications for their time in paid and unpaid work and their worktime disruptions. 
Finally, selection into working from home undoubtedly also shapes telecommuting's associations with mother's and fathers' paid and unpaid work, although in ways that are complicated to predict. Prior to the pandemic, for example, parents who actively sought out telecommuting as an alternative to the workplace may have had time demands at home that were particularly intensive or challenging to combine with a standard workplace schedule.

Conversely, parents who used telecommuting to extend their workday likely had time demands at work that were hard to fit in a standard schedule. Employers also exerted their own rationales on access to telecommuting, for example, to reward self-motivated and high-performing workers (Glass and Noonan 2016, Weeden 2005). These selection processes are gendered, with mothers expressing stronger motivations for telecommuting than fathers, often driven by family responsibilities (Mas and Pallais 2017), and fathers having more access on average to telecommuting (Alon et al. 2020).

During the pandemic, such selection processes were weaker, with state mandates and safety guidelines leaving many employers and employees with little control over where work could be done. Data from a Pew survey indicated that nearly two-thirds of all men and women working from home all or most of the time in October of 2020 said their workplace was currently closed or unavailable to them (Parker et al. 2020). In contrast to pre-pandemic, women were more likely to telecommute than men during the pandemic (Handwerker et al. 2020). COVID-19 also clearly changed the nature of work from home in ways critical to understanding its gendered effects; notably, school and daycare closings and social distancing mandates left working parents with many fewer institutional and informal supports to manage work and family demands (Collins et al. 2021, Petts et al. 2021, Yavorsky et al. 2021).

\section{Evidence on Telecommuting and Parents' Time Use}


Evidence on the effects of telecommuting on mothers' and fathers' time in paid and unpaid work prior to the pandemic is limited. At the cross section, data show that telecommuters tended to work longer hours than on-site workers (Noonan and Glass 2012). These estimates confound potential effects of telecommuting on work hours with selection factors into telecommuting that likely differ for mothers and fathers, as noted above. Fathers telecommuted more often than mothers pre-pandemic, and they more often used work to extend the workday into overtime hours (Glass and Noonan 2016). Telecommuting varied by factors that often go unobserved, like motivations for telecommuting and the availability of telecommuting; it was (and remained so in the pandemic) more common among managerial and professional workers with higher salaries and higher educational attainment (Bloom et al. 2020, Parker et al. 2020).

A few studies have relied on panel data to follow mothers (but not fathers) through the transition to parenthood, providing a more focused assessment of how telecommuting may shape work hours. Using two waves of the Understanding Society data from the UK, Chung and Van der Horst (2018) found that women who had access to telecommuting prior to childbirth were no more likely to remain employed after having a child, but they were somewhat less likely to reduce their work hours. Using data from a U.S. midwestern sample of employed pregnant women, Glass and Riley (1998) examined the association between several employer-provided work-family policies and employment following childbirth, and concluded that telecommuting was not among the most important of these policies in supporting maternal work. In particular, policies associated with hours reduction reduced job-leaving more consistently than policies related to flexibility, including telecommuting.

Based on the same longitudinal sample of midwestern pregnant women, Noonan et al. (2007) examined the relationship between employer-provided policies related to flexibility and 
time in housework and childcare. They looked cross-sectionally at both mothers' and fathers' housework and childcare, and estimated models of within-person change among mothers, providing a better accounting of unmeasured individual characteristics that may affect both policy use and domestic work. They found fairly weak evidence overall for policy effects, with a few exceptions, including increased childcare time among telecommuting mothers, suggesting that working from home was replacing nonparental childcare for at least part of the workweek. Results from earlier studies have been inconsistent on telecommuting's association with mothers' unpaid work (Silver 1993, Silver and Goldscheider 1994), although consistent in finding null associations with fathers' time in housework and childcare (Noonan et al. 2007, Silver 1993).

The massive shift to telecommuting in the pandemic has generated new research on work from home and gendered effects on time use. Telecommuting protected U.S. mothers from employment loss during the pandemic, reducing gender gaps in employment relative to on-site workers (Alon et al. 2021). In unpaid work, however, gathering evidence suggests that work from home reinforced or exacerbated gender disparities. An online poll conducted for the New York Times in April 2020 showed that although both mothers and fathers increased their time in housework and child care, the division of responsibility remained starkly gendered, even when both partners worked from home. When only one spouse worked remotely, telecommuting fathers reported far less involvement in domestic work than telecommuting mothers, consistent with the idea that gendered norms protect telecommuting fathers (Dunatchik et al. 2021). In line with these findings, a Pew national survey from October 2020 showed that, among telecommuting parents, mothers were twice as likely as fathers to report that they have a lot of childcare responsibilities while performing their paid job (Igielnik 2021). 
In sum, evidence on telecommuting's effect on mothers' and fathers' paid and unpaid work time prior to the pandemic is limited. The rise of telecommuting during the pandemic has led to new attention to this issue, although leaving open critical questions for gender equality in a post-pandemic labor market. Our main analysis expands on the telecommuting literature in significant ways. First, whereas much prior work focuses on women, we include an explicit gender comparison to address how telecommuting is associated with gender gaps in paid and unpaid work. Second, we make innovative use of data to better parse out the causal relationship between telecommuting and time use. Third, we rely on nationally representative time diaries for broader, more reliable, and finer-grained estimates of pre-pandemic time use (Robinson 2002). Finally, our pandemic analysis provides new information on telecommuting's association with family-related reductions in paid work time.

\section{OUR APPROACH}

Drawing broadly on work family literature and evidence specifically on telecommuting, we posit that telecommuting may allow more flexibility to manage competing demands of work and family and result in a more equal sharing of paid and unpaid work between mothers and fathers. At the same time, the combination of stronger normative pressures on mothers as caretakers and the blurring of work-home boundaries may exacerbate inequalities in parents' time use, leaving mothers more on task to attend to household labor. This might be especially the case for housework, which fathers seem more reluctant to take on than childcare (Chesley and Flood 2017). We expect telecommuting to disproportionately increase mothers' housework hours, multitasking, and work interruptions relative to fathers' and have a more proportionate impact on parents' childcare time, particularly when both partners work full-time. We examine 
these questions triangulating across data sources and samples and combining descriptive approaches with strategies designed to provide greater leverage on causal questions.

Our main analysis draws from nationally representative time diary data that provide rich details on the context of work that are less prone to error and bias than global recall (Robinson 2002). Diary data allow us to differentiate between workdays spent entirely at home and those that include a mix of home and on-site work more typical of telecommuting as an extenstion of the workday (Glass and Noonan 2016). We can also measure work disruptions, including the number of separate work activities across the diary day (fragmentation) and the presence of children while working. We estimate gender gaps in time use for parents in a matched sample and a telecommuting sample of the ATUS, and we examine variation in observed patterns for more egalitarian households with two full-time working parents and households with just a fulltime working father.

Our two ATUS samples allow us to better address concerns about selectivity and approximate causal relationships. In our matched sample from the 2003-18 ATUS, we compare telecommuting parents within occupational categories. This sample includes workers in jobs that could plausibly be done remotely, which is arguably the closest to a post-pandemic world. Models estimated with the matched sample account for the differences in the characteristics of mothers and fathers by telecommuting status that we can observe in the ATUS. To better account for unobserved factors, such as preferences for household labor or childcare, we draw on a subset of the 2017-18 ATUS who report ever telecommuting. We use this exogenous variation in diary day telecommuting among mothers and fathers to provide greater leverage on how telecommuting affects housework and childcare over the course of a day. The tradeoff is that this relatively small group of ever-telecommuters in 2017-2018 is likely less representative of future 
telecommuters than the matched sample. Differences in results using these two samples may be driven by unobserved characteristics in the matched sample and/or the differential effects of telecommuting among the universe of workers and ever-telecommuters.

Supplementary analyses rely on the CPS to describe gender patterns in telecommuting during the pandemic. Although we do not have ATUS-equivalent diary data for the pandemic, we have information on telecommuting, time in paid work, and parents' explanations of underemployment, in particular part-time status due to childcare or other family-related reasons. This provides an early look at the gendered implications of telecommuting's role in managing work and family in the pandemic, with potential implications for the future of work and family.

\section{DATA AND METHOD}

\section{Data and Samples}

Our main analysis draws on the ATUS, which provides time diaries and records in detail the nature and context of daily activities for a large representative sample of American workers (Hofferth et al. 2020). It prompts respondents to record their activities, the location of activities, and the presence of others over 24 hours. Our ATUS samples include partnered and unpartnered parents ages 21-60 with resident children $<18$, who worked for an employer for pay and reported regular work hours. We excluded self-employed respondents because the relationship between work and time flexibility is likely very different for workers with and without employers. We also dropped weekend diaries and respondents who worked less than two hours on the diary day to capture days structured more substantially around work.

Our matched sample $(N=12,519$ parents) draws from the 2003-2018 ATUS and includes two additional sample restrictions to generate plausible counterfactuals for telecommuting: First, we excluded respondents in occupations that cannot be done remotely, identified in our CPS 
sample as those in which fewer than $5 \%$ of workers switched to telecommuting during the pandemic (a list of these occupations is available upon request). Second, we excluded respondents who could not be matched on telecommuting status, that is, in occupational categories without at least one mother and one father working from home, working nonremotely, and splitting their work time between home and work. Our ever-telecommuter sample ( $N=405$ parents) uses supplements from the 2017-2018 ATUS that ask telecommuting questions, including: "Are there days when you work only at home?" We restrict this sample to parents who reported ever telecommuting for a full day.

In supplementary analyses, we use data from the monthly May to November 2020 CPS to document gender gaps in paid work time during the pandemic. The CPS is a survey of approximately 50,000 households each month, and the COVID-19 supplement included additional questions on telecommuting and job-leaving. Like our ATUS samples, our CPS pandemic sample ( $N=83,676$ person months) includes parents ages 21-60 with resident children $<18$ who worked for an employer for pay and reported regular work hours. Table A1 details sample construction for all samples.

\section{Measures}

\section{ATUS Measures}

Telecommuting. We define telecommuting on the basis of respondents working on their main job and reporting that their location was "home." We divide respondents into three groups: workplace, for whom all reported work activities on the diary day were at the workplace; mixed, for whom some work activities were at home and others at the workplace; and home, for whom all work activities were at home. We tested several other telecommuting taxonomies, including a binary telecommuting/workplace measure and categorization based on the duration of time 
telecommuting, and we found similar results for each. The 2017-2018 ATUS supplements also include a question "How often do you work only at home?" that allows us to control for the frequency of telecommuting in our ever-telecommuter sample. Table 1 presents descriptive statistics for all samples.

\section{[TABLE 1 ABOUT HERE]}

Time use. We define housework to include both core housework (such as cleaning, tidying, laundry, and cooking) and ancillary housework activities, such as household maintenance and vehicle maintenance. Prior research finds gender inequalities in both broadly and narrowly defined housework, but larger inequalities in the latter case (Bianchi et al. 2012), so our estimates are likely conservative. We create a measure of childcare that combines basic care activities of younger children (e.g., feeding, bathing) with activities relating to education (e.g., helping with a child's homework or attending a PTA meeting), health (e.g., sitting with a sick child), and associated travel of all minor children. These measurement strategies are commonly applied in the literature (e.g., Musick et al. 2016).

Paid work time is time spent on paid work on the diary day. We construct two measures that indicate competing work demands and divided attention: the fragmentation of work and the presence of children. Fragmentation is the number of separate work activities across diary day and captures the extent to which work is divided into spells (Flood et al. 2019). The presence of children while working is a summary of the time when respondents' children were present during work activities, based on the activity-level "who with" question. ATUS began recording copresence for work activities in 2011, so analyses of child presence are based on a 2011-2018 sample $(N=6,177)$. Time use outcomes are top-coded at the $99^{\text {th }}$ percentile to decrease the 
influence of extreme values. We examined the functional form of the relationships between time use and telecommuting by coding time use categorically, and the results are highly consistent.

Social and demographic characteristics. We control for work and demographic characteristics, as well as family composition. Work characteristics include occupation, weekly work hours, and weekly earnings. Demographics include age, whether a respondent graduated from four-year college, the age and number of the respondent's children in the household, race/ethnicity (non-Hispanic Black, Hispanic, and neither Black nor Hispanic), whether a respondent is married/cohabiting, and if the spouse/partner is employed full-time (35+ hours per week).

CPS Pandemic Measures

In May 2020, the CPS introduced a question that asks whether the respondent worked from home for pay at any time during the previous four weeks due to the pandemic, and we coded "yes" responses as working from home. This measure excludes workers whose telecommuting was not due to the pandemic, e.g., who had been telecommuting previously (about $15 \%$ of telecommuters prior to 2020 telecommuted full-time, according to our own calculations from the ATUS), and thus likely underestimates to some degree telecommuting during the pandemic. We assess two measures of work time: Work hours includes hours worked in all jobs in the week prior to interview. Family-related part-time work is a binary measure that captures the extent to which parents moved into part-time work because of childcare and other family/personal obligations.

\section{Analytical Strategy}

Estimates Based on the Matched Sample 
Our matched sample was constructed using coarsened exact matching (CEM). Like all matching methods, CEM aims to achieve balance on key variables between treatment and control groups, and in doing so reduce model dependence (Iacus et al. 2012). This is achieved by sorting observations into groups based on a matching variable (or variables) and discarding those that do not include all treatment and control groups. In our case, we match on occupation and discard strata that do not include the six combinations of our work location variables (workplace, mixed, home) by gender. Matching on detailed occupation alone excludes two thirds of the sample, so we first match by detailed occupation and, for those not initially matched, by a coarsened set of twenty-two occupational categories. This creates a sample in which it is possible to compare the time use patterns of parents working from home and the workplace in similar jobs.

Using the matched sample, we estimate models of time use by gender and work location. We control for family and demographic characteristics that may select respondents into telecommuting, including: age (and its quadratic), number and age of children, relationship status, spouse/partner's employment, race/ethnicity, education, and year. For all outcomes except work time, we also control for weekly earnings, usual weekly work hours and working part-time. All models are fully interacted with gender (making them identical to models estimated separately for mothers and fathers), and all estimates incorporate sampling weights. Sensitivity analyses assess variation in telecommuting's association with housework and childcare among partnered parents by their joint employment status, in particular, examining the notion that telecommuting may have a more gender equal effect on unpaid work among dual full-time earning parents, relative to couples in which the mother works part-time (there are too few couples with a part-time employed father to analyze separately, see Table 1).

Estimates Based on the Ever-Telecommuter Sample 
We estimate an analogous set of models to our main matched models with our evertelecommuting sample. Due to smaller samples, we do include interactions between controls and gender; we include only the interaction between gender and telecommuting status to assess gender differences in time use by telecommuting status. A key assumption of our estimation strategy is that, among this sample of mothers and fathers who report days when they work from home, selection into telecommuting on the diary day is unlikely driven by an inability to telecommute. Thus, after adjusting for the frequency of telecommuting, we should have two random groups of ever-telecommuters who do not differ systematically, with one group assigned to work from home and the other to work in the workplace. To test this assumption, we examined the observed differences between the two groups and found that only spousal employment varied substantially, which we include as a control in our models. Table A2 presents $\mathrm{T}$ tests of these comparisons.

\section{Estimates Based on the Pandemic Sample}

Because transitioning to working from home is arguably exogenous for many workers during the pandemic, we present descriptive means and differences in means to examine whether the shift to telecommuting following the onset of the pandemic has equally impacted mothers and fathers. Specifically, we estimate gender gaps in paid work hours and family-related parttime work by work location. CPS interviews households for up to four consecutive months, so we cluster standard errors at the respondent level, and use the CPS monthly sampling weights.

\section{RESULTS}

\section{Telecommuting Prior to the Pandemic}

Figure 1 plots time use by gender and telecommuting status from our matched sample. Panel A shows predicted time use by gender, and Panel B shows predicted differences in time 
use between mother and fathers. Estimates are derived from OLS models of time use with our full set of controls; full model results are shown in Table A3.

\section{[FIGURE 1 ABOUT HERE]}

Panel A shows that mothers and fathers who work from home only spend more time on both childcare and housework than parents in the workplace or who split their time between locations. Mothers working from home only during the diary day spend on average 106 minutes on childcare and 85 minutes on housework, compared to 82 and 54 minutes among fathers working from home, respectively. Mothers in the workplace spend, on average, 87 minutes on childcare and 61 minutes on housework, whereas fathers spend 52 minutes and 38 minutes, respectively. Mothers who split their time between home and the workplace spend, on average, 97 minutes on childcare and 66 minutes on housework, whereas fathers spend 59 minutes and 39 minutes, respectively.

The relationship between gender gaps in time use and work location are quite different for housework and childcare, as shown in Panel B. Gender gaps in childcare are significantly smaller among parents working from home only versus the workplace, by 11 minutes (i.e., mothers working from home do about 20 more minutes of childcare than fathers working from home vs. over 30 more minutes among mothers and fathers working on-site). Gender gaps in housework, by contrast, are significantly larger among those working from home, by 9 minutes relative to those working on-site. Gender gaps in childcare and housework for parents who split their time between home and the workplace are similar to those for parents in the workplace.

Mothers and fathers who work from home only spend substantially less time in paid work, on average, than mothers and fathers in the workplace, with home-only mothers working 64 fewer minutes and home-only fathers 47 fewer minutes, relative to mothers and fathers in the 
workplace, respectively (Panel A). Parents who split their time between home and the workplace work the longest hours, with fathers working an additional 33 minutes compared to fathers exclusively in the workplace, and mothers working an additional 28 minutes, consistent with the notion that this form of telecommuting often serves to extend the workday (Glass and Noonan 2016). Relative to the workplace only, the gender gap in paid work time is 17 minutes larger and statistically significant for parents working from home only, whereas gaps for parents who split their time between home and the workplace are similar (Panel B).

Work disruptions are far more common among telecommuters than parents in the workplace. Mothers and fathers working from home have children present during worktime for 28 and 21 minutes, respectively, and mothers and fathers who split their time between home and the workplace have children present for 18 and 12 minutes. This is compared to just a few minutes on average for parents in the workplace (Panel A). Gender gaps in child presence are on average 5 minutes larger for both exclusive telecommuters and parents splitting their time between home and the workplace, with both gaps statistically significant (Panel B). Despite working shorter workdays, mothers and fathers working from home also experience more fragmentation of their workday, working on average 0.4 and 0.5 additional spells compared to parents in the workplace (Panel A). Gender gaps in work spells do not differ significantly among those working from home, the workplace, or both (Panel B).

Estimates from our ever-telecommuter sample shown in Table 2 provide further evidence that work location shapes gender inequalities in time use. The interaction terms between gender and work location provide estimates of gaps in time use between mothers and fathers working at home only and those splitting their time between home and the workplace, relative to parents working in the workplace only on the diary day. Gender gaps in childcare among parents 
working from home only are 40 minutes smaller than those working on-site only, and gender gaps in housework are 37 minutes greater (both differences are statistically significant). This pattern is consistent with key findings from our matched models, although the magnitude of differences is larger. Among parents who split their time on the diary day between home and the workplace, there are no differences in childcare gaps relative to parents in the workplace, and housework gaps are larger, on a scale similar to parents working from home only.

\section{[TABLE 2 ABOUT HERE]}

Again, consistent with the matched sample, gender gaps in paid work time appear larger on home-only work days (with telecommuting mothers working less), although here the difference is not statistically significant. For parents who work in both locations, the gender gap is 74 minutes, and this difference is significant. Gender gaps in work disruptions are also larger for telecommuters in this sample. The gender gap in working with a child present is statistically significantly larger among parents working from home only relative to those in the workplace only, by 23 minutes. And the gender gap in work spells is statistically significantly larger for parents who split their time between home and the workplace relative to those in the workplace only, by 1.7 spells.

To summarize, relative to working on-site, working from home only is associated with decreased gender gaps in childcare and increased gender gaps in housework across samples. Results are suggestive but more uncertain in relation to paid work time, with estimated gender gaps in both samples larger for parents who work from home only, but imprecise in the evertelecommuter sample. Across samples, mothers also experience disproportionately more work disruptions when working from home. Estimates of gender gaps in time use are typically larger in the ever-telecommuter sample. It is possible that the ever-telecommuters are more able to 
structure their schedules such that they spend more time on household labor on telecommuting days than on non-telecommuting days. As noted earlier, the ever-telecommuter sample is also a narrower group than the potential telecommuters represented in the matched analysis, which may further play into estimates of effect sizes.

\section{Heterogeneous Effects by Couples' Work Arrangements}

In sensitivity analyses, we assess variation in telecommuting's association with housework and childcare among partnered parents by their joint employment status. We compare two subgroups: 1) parents both working full-time, and 2) fathers working full-time and mothers working part-time. For families in which both parents work full-time, results reflect those of the full matched sample (see Figure A1 for full set of predicted values): Relative to parents working on-site, childcare gaps are significantly smaller for parents working from home, and housework and work disruption gaps appear larger, although do not meet standard levels of statistical significance. For families in which mothers work part-time, estimated gender gaps in childcare appear larger among those working from home versus the workplace, in contrast to our main results, although differences are not statistically significant. Gender gaps in housework and work disruptions among those working from home are statistically significantly larger than gaps among those working on-site, consistent with our main results. Overall, this assessment provides a fairly consistent pattern of estimated effects across couple-level work arrangements, with some suggestive evidence that telecommuting does more to reduce gender gaps in childcare when both parents are employed full-time.

\section{Telecommuting During the Pandemic}

Drawing from COVID supplements to the CPS, Figure 2 explores the relationship between telecommuting and paid work hours among parents between May and November 2020. 
Panel A plots unadjusted mean hours worked last week and the proportion of mothers and fathers working part-time for family reasons, and Panel B plots the difference in means between mothers and fathers in work hours and shifts to part-time work. These data allow us to differentiate between those who worked from home for any reason over the last four weeks due to the pandemic and those who did not.

\section{[FIGURE 2 ABOUT HERE]}

Telecommuting is associated with more paid work hours among mothers and fewer among fathers (Panel A): Mothers working from home work on average 39 hours per week and 37 hours when working from the workplace, whereas fathers work 42 and 43 hours per week, respectively. We also see gender differences in associations between telecommuting and shifting to part-time work for family-related reasons: $5 \%$ of telecommuting mothers and $9 \%$ of nontelecommuting mothers work part-time because of family reasons, whereas for fathers in any location the figure is $1 \%$. This translates into smaller gender gaps in work hours and shifts to part-time work for family-related reasons for telecommuting vs. non-telecommuting workers (Panel B): Gender gaps in paid work hours are 2.5 hours per week smaller for telecommuting mothers than for non-telecommuting mothers, and gender gaps in part-time work for family reasons are 3.5 percentage points smaller for mothers working from home.

These findings show that mothers who worked from home during the pandemic were better able to maintain attachment to work than mothers in the workplace, but they also point to gender inequalities in care responsibilities. Although the CPS does not have data on unpaid work hours, the lack of change in fathers' work hours with work location, despite school closures and various disruptions to formal and informal care networks, suggests that fathers are less responsive to the competing demands of home and work (e.g., Musick and Jeong 2021). 


\section{CONCLUSION}

The COVID-19 crisis has resulted in an unprecedented shift to remote work, and at least some of the pandemic-related shift to telecommuting is likely to persist for some time. We explored the implications of telecommuting for gender equality in parents' paid and unpaid work. We reasoned that on the one hand, telecommuting may give mothers and fathers more flexibility to manage competing demands of work and family and result in a more equal sharing of paid and unpaid work. On the other hand, the combination of stronger normative pressures on mothers as caretakers and the lack of physical separation between work and home may leave mothers more on task to attend to household labor and exacerbate inequalities in parents' time use. Studies investigating these questions prior to the pandemic produced inconsistent results (e.g., Noonan et al. 2007, Silver and Goldscheider 1994), and early reports of pandemic-related work and care dislocations on gender gaps in household labor have also been mixed (Carlson et al. 2020, Miller 2020). This paper advances our understanding of telecommuting in significant ways, by: including an explicit comparison of paid and unpaid work and the potential tradeoffs associated with telecommuting; making innovative use of data to better assess causality; and relying on nationally representative time diaries for broader, more reliable, and finer-grained estimates of pre-pandemic time use.

Our analysis of time use data prior to the pandemic provides some evidence in support of the idea that telecommuting reduces gender disparities at home. We show that on diary days worked exclusively from home, mothers and fathers spend more time in childcare than on days at the workplace, and the difference is disproportionately large for fathers, particularly when both parents work full-time. However, we also find that working exclusively from home on the diary day is associated with larger increases in housework among mothers than fathers, resulting in 
greater gender gaps in housework. Discrepant findings in these two domains are consistent with prior evidence on differences in the processes governing mothers' and fathers' time in housework and childcare (Chesley and Flood 2017). Parents experience greater enjoyment and meaning in time with children than in most other daily activities (Musick et al. 2016), and fathers have been more responsive to childcare needs than those related to the more onerous aspects of housekeeping (Altintas and Sullivan 2017, Goldscheider et al. 2015).

Time diary data further suggest that working exclusively from home is associated with larger gender gaps in paid work time (although results from the ever-telecommuter sample miss conventional levels of statistical significance). Across samples, we found consistent evidence that working from home increases work time in the presence of children and does so disproportionately for mothers. Detailed data on the sequencing of activities and presence of others in activities shed new light on the nature of telecommuting. Critically, these data allowed us to measure gendered differences in disruptions to work time - a critical dimension of work that may adversely affect mothers' productivity and stress (Lyttelton et al. 2020). It also allowed us to parse out telecommuters who spent part of their day at home and part in the workplace. Consistent with prior literature (Glass and Noonan 2016), this form of telecommuting appears to more often extend the workday, resulting in longer work hours among this group than either those working exclusively from home or the workplace. The unpaid time of these telecommuters tended to look more similar to those who worked exclusively on-site.

COVID-19 led to a massive increase in telecommuting and simultaneous breakdown in institutional support for families with children, resulting in unprecedented challenges in managing work and caregiving for many (Collins et al. 2021). Our analysis of paid work from May to November 2020 showed that telecommuting mothers were working longer hours and 
were less likely to be working part-time for family reasons than non-telecommuting mothers, whereas fathers' work time was not responsive to work location. These results are consistent with Alon et al. (2021)'s description of women's work hours in the pandemic, and suggest that telecommuting provided a mechanism for mothers to maintain greater attachment to the labor force. This is an important finding, although it is in the context of substantially more labor force withdrawals and reductions in paid work time for family-related reasons among mothers than fathers, irrespective of work arrangement (Heggeness 2020, Landivar et al. 2020). They exemplify a pattern that extends beyond the pandemic: "When unexpected family needs arise, mothers step in" (Miller 2020).

Putting the evidence together, the answer to whether telecommuting results in a more or less equal sharing of paid and unpaid between mothers and fathers involves trade-offs. Our COVID-19 analysis suggests that telecommuting may allow some mothers to remain in the labor force who would otherwise drop out or cut back to part-time status. Our assessment of time diaries prior to the pandemic shows that it disproportionately increases childcare time for fathers, closing the gender gap in childcare hours relative to parents working on-site. The trade-offs for telecommuting mothers include lost wages resulting from time diverted from paid to unpaid work (Van den Berg et al. 2006). They also include disruptions to paid work time, which were greater among telecommuting mothers than fathers even prior to the pandemic and its school and daycare closures. Multitasking and work interruptions are associated with emotional strain and role conflict (Offer and Schneider 2011), and may be contributing factors to the higher anxiety, loneliness, and depressed feelings reported by telecommuting mothers versus fathers during the pandemic (Lyttelton et al. 2020). 
This study sheds new light on telecommuting, nonetheless is limited by data constraints that leave more research to be done. First, our pandemic analysis is limited to paid work time as our data do not allow us to directly examine gender gaps in childcare or housework by telecommuting status. Second, because the ATUS does not include information on telecommuting of others in the household, we are not able to consider partners' telecommuting status, or examine the dynamics of dual-telecommuting households, which COVID-19 has made relatively common. Third, our causal estimates from the ever-telecommuters sample rely on the assumption that our observation of telecommuting is randomized after adjusting for telecommuting frequency. Potentially more limiting for drawing conclusions relevant to the pandemic and beyond, these estimates are based on a sample of regular telecommuters, and they may not generalize to what has become a much broader group of workers. Here, our matched sample does a better job, and results across these samples are consistent. Finally, our study provides only limited insight into why telecommuting leads to gender disparities in time use. Understanding the source of gender gaps among telecommuters during COVID-19 is an important task for further research, and one that is likely to have sustained impact.

Telecommuting will likely become a more common part of work and family life after the pandemic. Maintaining office space is costly for organizations, and for some the shift to remote work during the pandemic has provided a test case for the benefits of a remote workforce. A recent survey found that $56 \%$ of hiring managers feel that remote working during the pandemic has gone better than expected, and more hiring managers say remote work has increased than decreased productivity (Ozimek 2020). The pace of technological innovations related to remote work has also increased markedly (Bloom et al. 2020), signaling greater capacity and productivity in remote work moving forward. One recent study estimated that after the pandemic 
$22 \%$ of work days will be remote (Barrero et al. 2020). Our findings point to gendered tradeoffs in telecommuting before and during the pandemic and provide insight into how greater choice in work location might play out post-pandemic.

The current crisis has shed harsh light on the weaknesses of our institutional support system for families. Other rich countries outside the U.S. do much more to alleviate conflicts between work and family that fall disproportionately on women, including subsidized childcare, paid sick leaves for families with children, and recognition in the workplace that men as well as women need more flexibility in work hours to care for children (Gornick and Meyers 2003, Musick et al. 2020). Addressing these gaps is a critical task both for reducing gender inequalities in work and supporting the next generation. Compared to pre-pandemic, telecommuting will likely become more common post-pandemic, and the reopening of schools and social networks will mitigate the strains of working from home associated with COVID-19. It will take a stronger infrastructure of care in this country (Slaughter 2021), however, to fully address the gendered tradeoffs that have long factored into how U.S. families manage the competing demands of work and family.

\section{REFERENCES}

Allen, T. D., Golden, T. D. \& Shockley, K. M. (2015). How effective is telecommuting? Assessing the status of our scientific findings. Psychological Science in the Public Interest, 16, 40-68.

Alon, T., Coskun, S., Doepke, M., Koll, D. \& Tertilt, M. (2021) From Mancession to Shecession: Women's employment in regular and pandemic recessions. Cambridge, MA: National Bureau of Economic Research Working Paper Series No. 28632. 
Alon, T. M., Doepke, M., Olmstead-Rumsey, J. \& Tertilt, M. (2020) The impact of COVID-19 on gender equality. Cambridge, MA: National Bureau of Economic Research Working Paper Series No. 26947.

Altintas, E. \& Sullivan, O. (2017). Trends in fathers' contribution to housework and childcare under different welfare policy regimes. Social Politics: International Studies in Gender, State \& Society, 24, 81-108.

Barrero, J. M., Bloom, N. \& Davis, S. J. (2020) Why working from home will stick. Chicago, IL: University of Chicago, Becker Friedman Institute for Economics Working Paper.

Bianchi, S. M. (2000). Maternal employment and time with children: Dramatic change or surprising continuity? Demography, 37, 401-414.

Bianchi, S. M., Sayer, L. C., Milkie, M. A. \& Robinson, J. P. (2012). Housework: Who did, does or will do it, and how much does it matter? Social Forces, 91, 55-63.

Bianchi, S. M. \& Wight, V. R. (2011) The long reach of the job: Employment and time for family life. In K. Christensen \& B. Schneider (Eds.), Workplace flexibility: Realigning 20th-century jobs for a 21st-century workforce. (pp. 17-42), Ithaca, NY: Cornell University Press.

Blair-Loy, M. (2003). Competing devotions: Career and family among women executives: Harvard University Press.

Bloom, N., Davis, S. J. \& Zhestkova, Y. (2020). Covid-19 shifted patent applications toward technologies that support working from home. University of Chicago, Becker Friedman Institute for Economics Working Paper.

Brenan, M. (2020) U.S. workers discovering affinity for remote work. GALLUP. Washington, DC. 
Carlson, D. L., Petts, R. \& Pepin, J. R. (2020) U.S. couples' divisions of housework and childcare during COVID-19 pandemic. SocArXiv.

Chesley, N. \& Flood, S. (2017). Signs of change? At-home and breadwinner parents' housework and child - care time. Journal of Marriage and Family, 79, 511-534.

Chung, H. \& Van der Horst, M. (2018). Women's employment patterns after childbirth and the perceived access to and use of flexitime and teleworking. Human Relations, 71, 47-72.

Collins, C., Landivar, L. C., Ruppanner, L. \& Scarborough, W. J. (2021). COVID-19 and the gender gap in work hours. Gender, Work \& Organization, 28, 101-112.

Craig, L. (2007). How employed mothers in Australia find time for both market work and childcare. Journal of Family and Economic Issues, 28, 69-87.

Craig, L. \& Mullan, K. (2011). How mothers and fathers share childcare: A cross-national timeuse comparison. American Sociological Review, 76, 834-861.

Craig, L. \& Mullan, K. (2013). Parental leisure time: A gender comparison in five countries. Social Politics, 20, 329-357.

Dunatchik, A., Gerson, K., Glass, J., Jacobs, J. A. \& Stritzel, H. (2021). Gender, parenting, and the rise of remote work during the pandemic: Implications for domestic inequality in the United States. Gender \& Society, 35, 194-205.

Eavis, P. \& Haag, M. (2021) After pandemic, shrinking need for office space could crush landlords. The New York Times. New York, NY.

Flood, S., Meier, A. \& Musick, K. (2019). Reassessing parents' leisure quality with direct measures of well-being: Do children detract from parents' down time? Journal of Marriage and Family, 82, 1326-1339. 
Gajendran, R. S. \& Harrison, D. A. (2007). The good, the bad, and the unknown about telecommuting: meta-analysis of psychological mediators and individual consequences. Journal of Applied Psychology, 92, 1524.

Glass, J. L. \& Noonan, M. C. (2016). Telecommuting and earnings trajectories among American women and men 1989-2008. Social Forces, 95, 217-250.

Glass, J. L. \& Riley, L. (1998). Family responsive policies and employee retention following childbirth. Social Forces, 76, 1401-1435.

Goldin, C. (2014). A grand gender convergence: Its last chapter. American Economic Review, 104, 1091-1119.

Goldscheider, F., Bernhardt, E. \& Lappegård, T. (2015). The gender revolution: A framework for understanding changing family and demographic behavior. Population and Development Review, 41, 207-239.

Gornick, J. C. \& Meyers, M. K. (2003). Families that work: Policies for reconciling parenthood and employment, New York, NY: Russell Sage Foundation.

Handwerker, E. W., Meyer, P. B. \& Piacentini, J. (2020). Employment recovery in the wake of the COVID-19 pandemic. Monthly Labor Review, 143, 1.

Heggeness, M. L. (2020). Estimating the immediate impact of the COVID-19 shock on parental attachment to the labor market and the double bind of mothers. Review of Economics of the Household, 18, 1053-1078.

Hofferth, S. L., Flood, S. M. \& Sobek, M. (2020) American Time Use Survey data extract builder: Version 2.8 [dataset]. College Park, MD: University of Maryland and Minneapolis, MN: IPUMS. 
Hook, J. L. (2010). Gender inequality in the welfare state: Sex segregation in housework, 19652003. American Journal of Sociology, 115, 1480-1523.

Iacus, S. M., King, G. \& Porro, G. (2012). Causal inference without balance checking: Coarsened exact matching. Political Analysis, 1-24.

Igielnik, R. (2021) A rising share of working parents in the US say it's been difficult to handle child care during the pandemic. Washington, DC: Pew Research Center.

Ishizuka, P. \& Musick, K. (2021). Occupational inflexibility and women's employment during the transition to parenthood. Demography, Forthcoming.

Kim, S. S., Galinsky, E. \& Pal, I. (2020) One kind word: Flexibility in the time of COVID-19. New York, NY: Families and Work Institute.

Kroska, A. (2003). Investigating gender differences in the meaning of household chores and child care. Journal of Marriage and Family, 65, 456-473.

Kühhirt, M. (2012). Childbirth and the long-term division of labour within couples: How do substitution, bargaining power, and norms affect parents' time allocation in West Germany? European Sociological Review, 28, 565-582.

Landivar, L. C., Ruppanner, L., Scarborough, W. J. \& Collins, C. (2020). Early signs indicate that COVID-19 is exacerbating gender inequality in the labor force. Socius, 6, 1-3.

Lyttelton, T., Zang, E. \& Musick, K. (2020) Before and during COVID-19: Telecommuting, work-family conflict, and gender equality. Council on Contemporary Families.

Marshall, J., Burd, C. \& Burrows, M. (2021) Those who switched to telework have higher income, education and better health. America counts: Stories behind the numbers. U.S. Census Bureau. 
Mas, A. \& Pallais, A. (2017). Valuing alternative work arrangements. American Economic Review, 107, 3722-3759.

Mattingly, M. J. \& Blanchi, S. M. (2003). Gender differences in the quantity and quality of free time: The US experience. Social Forces, 81, 999-1030.

Miller, C. C. (2020) Nearly half of men say they do most of the home schooling. 3 percent of women agree., The New York Times. New York, NY.

Miller, C. C. \& Rampell, C. (2013) Yahoo orders home workers back to the office. The New York Times. New York, NY.

Musick, K., Bea, M. D. \& Gonalons-Pons, P. (2020). His and her earnings following parenthood in the United States, Germany, and the United Kingdom. American Sociological Review, 85, 639-674.

Musick, K. \& Jeong, W. (2021) His and her long work hours and short-term employment changes following first birth., Population Association of America Annual Meeting.

Musick, K., Meier, A. \& Flood, S. (2016). How parents fare: Mothers' and fathers' subjective well-being in time with children. American Sociological Review, 81, 1069-1095.

Noonan, M. C. (2001). The impact of domestic work on men's and women's wages. Journal of Marriage and Family, 63, 1134-1145.

Noonan, M. C., Estes, S. B. \& Glass, J. L. (2007). Do workplace flexibility policies influence time spent in domestic labor? Journal of Family Issues, 28, 263-288.

Noonan, M. C. \& Glass, J. L. (2012). The hard truth about telecommuting. Monthly Labor Review, 135, 38 . 
Offer, S. \& Schneider, B. (2011). Revisiting the gender gap in time-use patterns: Multitasking and well-being among mothers and fathers in dual-earner families. American Sociological Review, 76, 809-833.

Ozimek, A. (2020) The future of remote work. Social Science Research Network Working Paper.

Parker, K., Horowitz, J. M. \& Minkin, R. (2020) How the coronavirus outbreak has - and hasn't changed the way Americans work. New York, NY: Pew Research Center.

Pettit, B. \& Hook, J. L. (2009). Gendered tradeoffs: Women, family, and workplace inequality in twenty-one countries, New York, NY: Russell Sage Foundation.

Petts, R. J., Carlson, D. L. \& Pepin, J. R. (2021). A gendered pandemic: Childcare, homeschooling, and parents' employment during COVID-19. Gender, Work \& Organization, forthcoming.

Robinson, J. P. (2002) The time-diary method. Time use research in the social sciences. (pp. 4789), Berlin, Germany: Springer.

Russell, H., O'Connell, P. J. \& McGinnity, F. (2009). The impact of flexible working arrangements on work-life conflict and work pressure in Ireland. Gender, Work \& Organization, 16, 73-97.

Sayer, L. C., Bianchi, S. M. \& Robinson, J. P. (2004). Are parents investing less in children? Trends in mothers' and fathers' time with children. American Journal of Sociology, 110, 1-43.

Silver, H. (1993) Homework and domestic work. Sociological Forum. (pp. 181-204): Springer.

Silver, H. \& Goldscheider, F. (1994). Flexible work and housework: Work and family constraints on women's domestic labor. Social Forces, 72, 1103-1119. 
Slaughter, A.-M. (2021) Rosie could be a riveter only because of a care economy. Where is ours? , The New York Times. New York, NY.

Sullivan, O. (2013). What do we learn about gender by analyzing housework separately from child care? Some considerations from time-use evidence. Journal of Family Theory \& Review, 5, 72-84.

Torr, B. M. \& Short, S. E. (2004). Second births and the second shift: A research note on gender equity and fertility. Population and Development Review, 30, 109-130.

Townsend, N. (2002). Package deal: Marriage, work and fatherhood in men's lives, Philadelphia, PA: Temple University Press.

U.S. Bureau of Labor Statistics (2019) Table 6. Employed persons working at home, workplace, and time spent working at each location by full- and part-time status and sex, jobholding status, and educational attainment, 2018 annual averages. Economic News Release. Washington, DC.

Van den Berg, B., Brouwer, W., Van Exel, J., Koopmanschap, M., Van den Bos, G. A. \& Rutten, F. (2006). Economic valuation of informal care: lessons from the application of the opportunity costs and proxy good methods. Social Science \& Medicine, 62, 835-845.

Weeden, K. A. (2005). Is there a flexiglass ceiling? Flexible work arrangements and wages in the United States. Social Science Research, 34, 454-482.

Yavorsky, J. E., Qian, Y. \& Sargent, A. C. (2021). The gendered pandemic: The implications of COVID-19 for work and family. Sociology Compass, 15, e12881. 
Table 1. Descriptive Statistics for Matched, Ever-Telecommuter, and Pandemic Samples

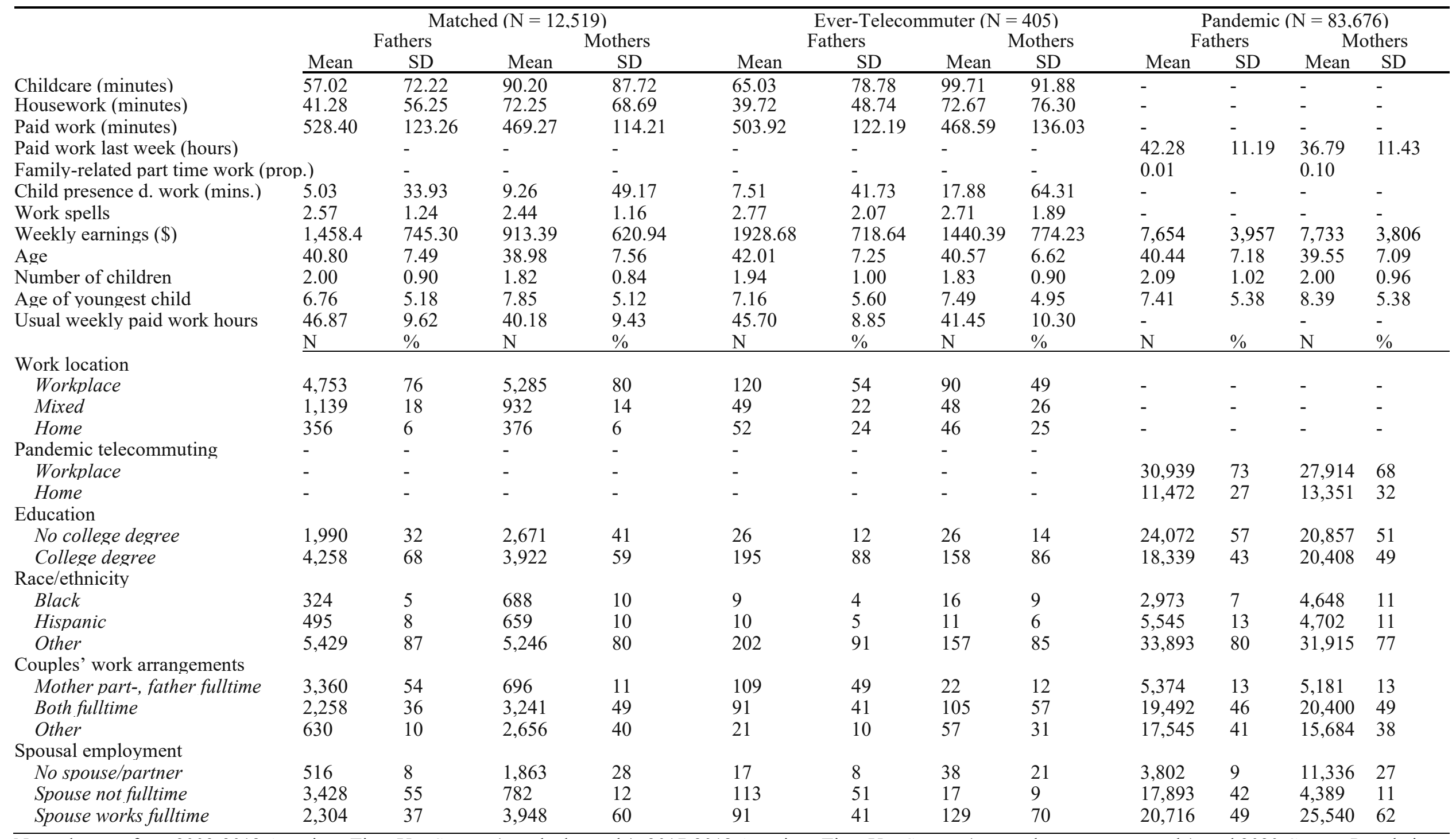

Note: data are from 2003-2018 American Time Use Survey (matched sample), 2017-2018 American Time Use Survey (ever -telecommuter sample), and 2020 Current Population

Survey (pandemic sample). 
Table 2. Time Use by Gender and Work Location among Ever-Telecommuters

\begin{tabular}{|c|c|c|c|c|c|}
\hline & Childcare & Housework & Paid work & $\begin{array}{l}\text { Child presence during } \\
\text { work }\end{array}$ & Work spells \\
\hline \multicolumn{6}{|c|}{ Work location: (ref. $=$ workplace) } \\
\hline \multirow[t]{2}{*}{ Mixed } & -4.93 & -5.30 & $62.46 * *$ & $17.36 *$ & 0.41 \\
\hline & $(12.53)$ & $(9.75)$ & $(20.90)$ & $(7.42)$ & $(0.35)$ \\
\hline \multirow[t]{2}{*}{ Home } & $57.58 * *$ & -13.02 & -22.16 & $22.34 *$ & $-0.93 *$ \\
\hline & $(15.47)$ & $(12.03)$ & $(25.79)$ & $(9.16)$ & $(0.44)$ \\
\hline \multirow[t]{2}{*}{ Mother (vs. father) } & $39.66 * *$ & 7.19 & -10.24 & -2.91 & -0.61 \\
\hline & $(11.50)$ & $(8.95)$ & $(19.17)$ & $(6.81)$ & $(0.32)$ \\
\hline \multicolumn{6}{|c|}{ Mother x work location: (ref. = workplace) } \\
\hline \multirow[t]{2}{*}{ Mixed } & -2.07 & $38.09 * *$ & $-73.96 *$ & 17.36 & $1.74 * *$ \\
\hline & $(18.69)$ & $(14.54)$ & $(31.16)$ & $(11.07)$ & $(0.53)$ \\
\hline \multirow[t]{2}{*}{ Home } & $-39.60 *$ & $36.83 *$ & -28.84 & $23.27 *$ & 0.86 \\
\hline & $(19.69)$ & $(15.32)$ & $(32.84)$ & $(11.66)$ & $(0.56)$ \\
\hline $\mathrm{N}$ & 405 & 405 & 405 & 405 & 405 \\
\hline
\end{tabular}

Note: $* *=p .<0.01, *=p .<0.05$. The models are estimated using OLS. Spousal employment and frequency of telecommuting are included as controls and are not interacted with gender. 
Figure 1. Predicted Parents' Time Use by Work Location and Gender
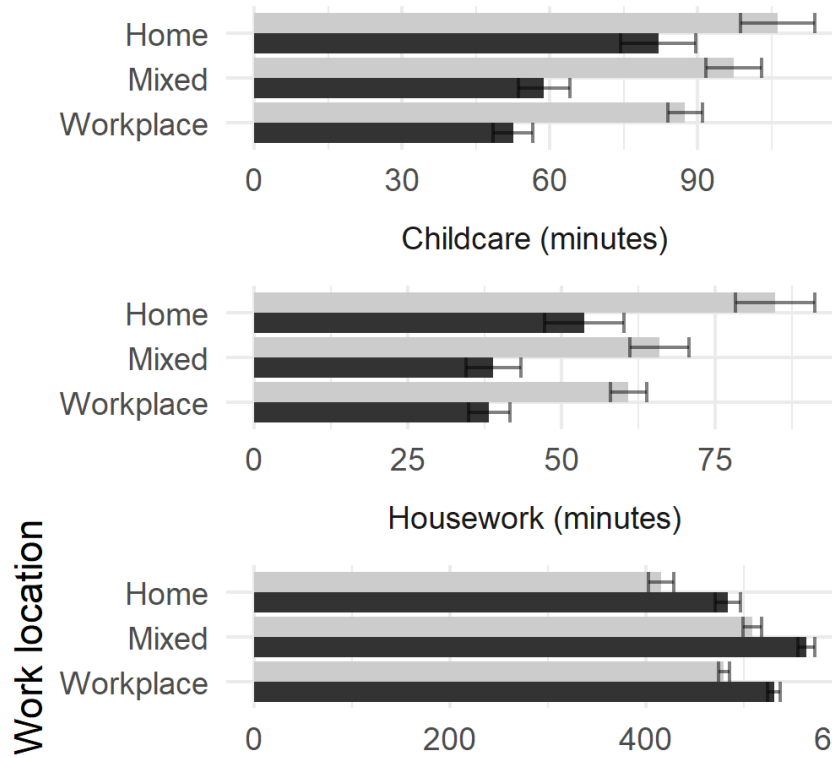

$\stackrel{3}{3}$

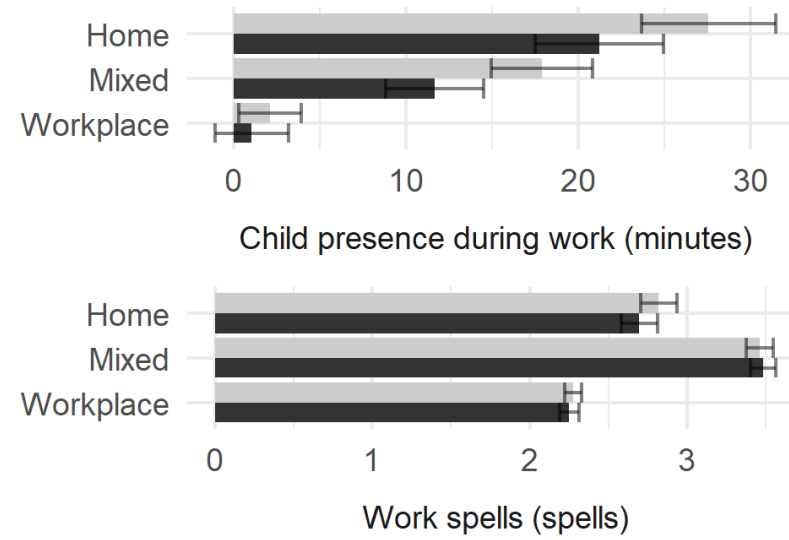

A. Time use

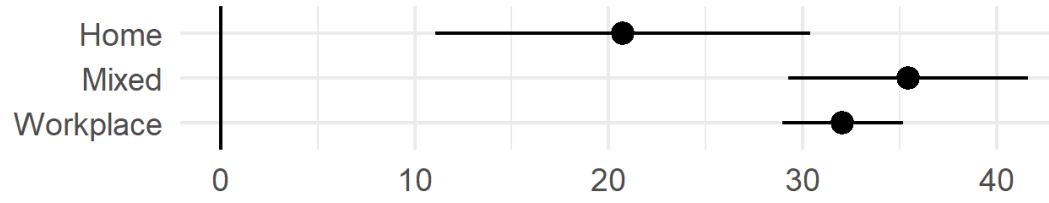

Childcare (minutes)*

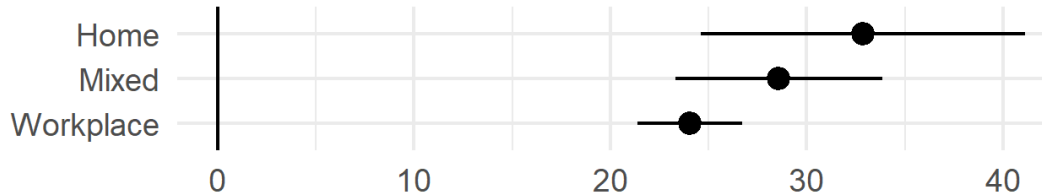

Housework (minutes)

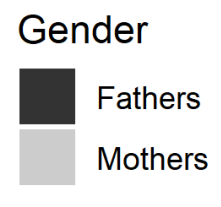

Home

Mixed

Workplace

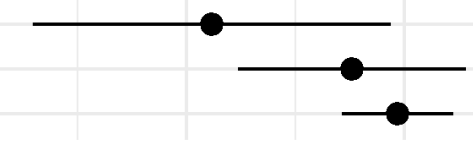

$-60$

$-40$

$-20$

0

Paid work (minutes) ${ }^{\star}$

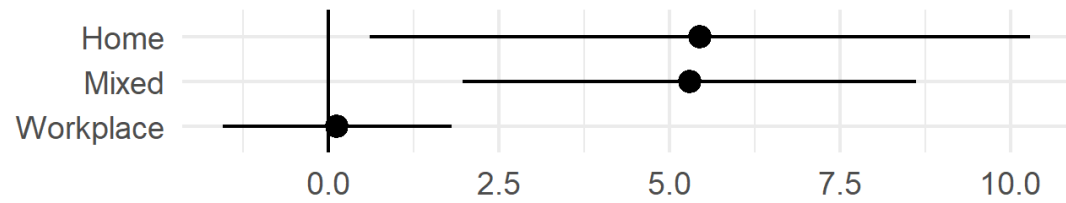

Child presence during work (minutes) ${ }^{*} \dagger$

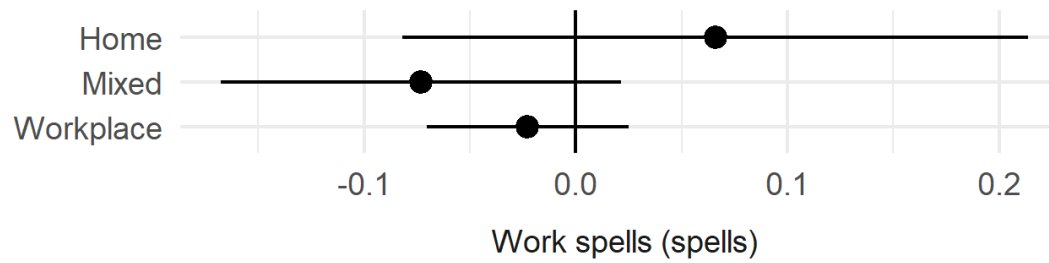

B. Gender gaps

Note: Data are from the 2003-2018 American Time Use Survey matched sample, N = 12,519. Panel A shows predicted time use by gender, and Panel B shows predicted differences in time use between mother and fathers. Predicted values are derived from OLS models with controls for age, race/ethnicity, education, earnings, partner status, and number of children, ${ }^{*}=p<0.05$ difference between home and workplace gender gaps in matched estimates. $\dagger=p<0.05$ difference between mixed and workplace gender gaps. Full models are presented in Table A3. 
Figure 2. Gender Gaps in Work Time By Work Location During the Pandemic

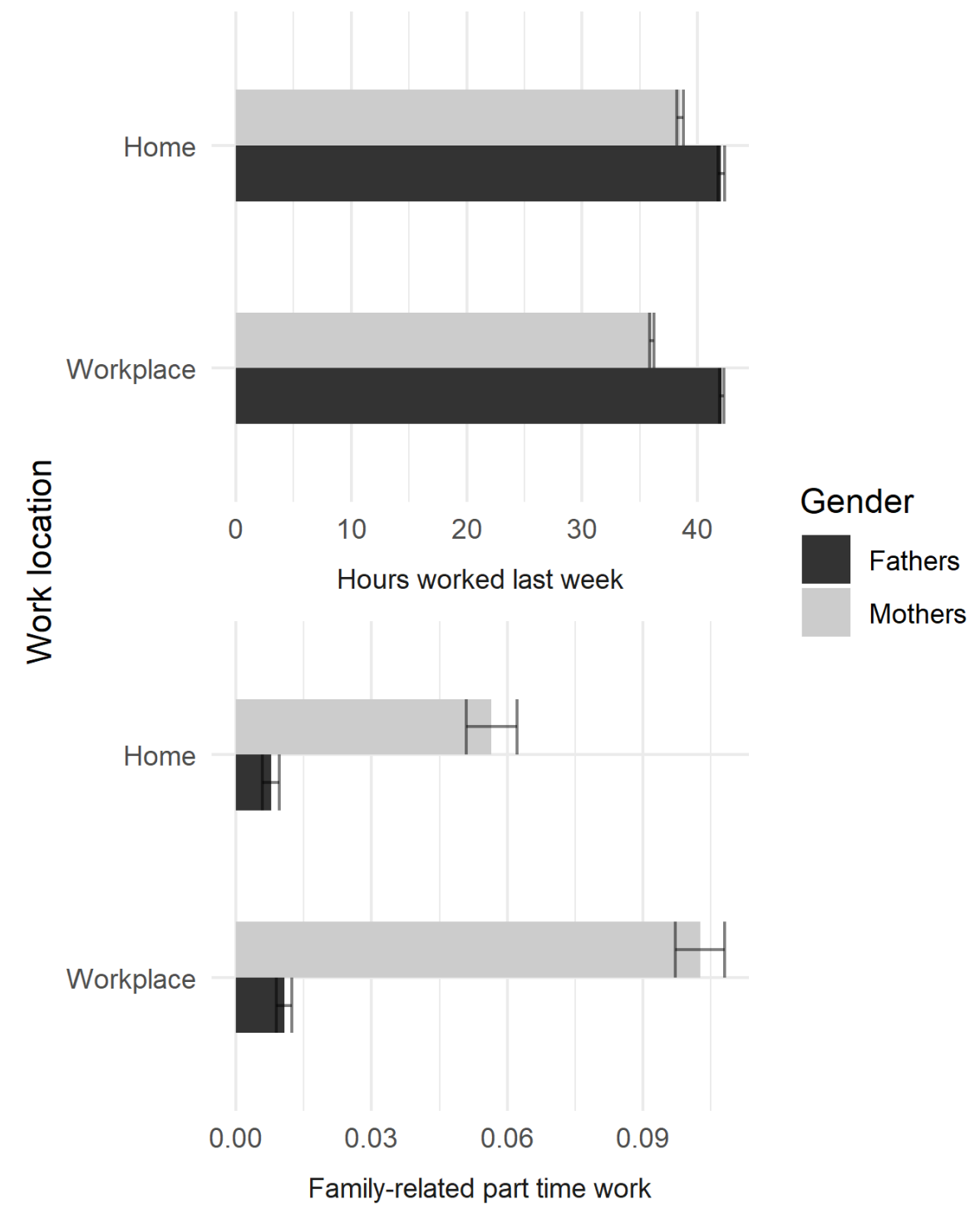

A. Time use
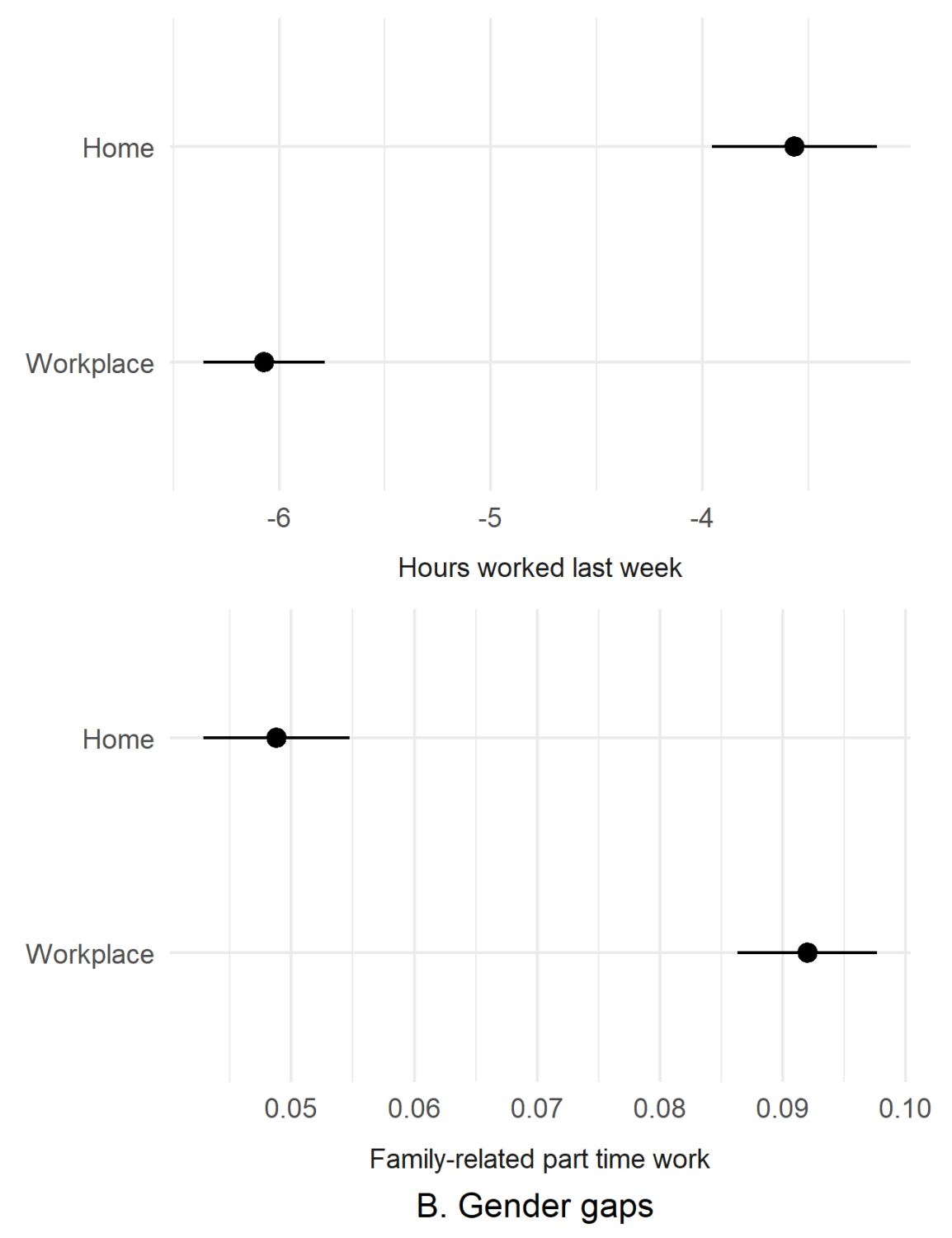

Note: Data are from the May - November 2020 Current Population Survey pandemic sample, N = 83,676. Panel A shows time use by gender, and Panel B shows differences in time use between mother and fathers. Estimates are unadjusted means/proportions and differences in means/proportions. 


\section{APPENDIX}

Table A1. Sample Construction and Characteristics

\begin{tabular}{|c|c|c|}
\hline Matched 2003-18 ATUS Sample & Ever-Telecommuter 2017-18 ATUS Sample & Pandemic May-Nov. 2020 CPS Sample \\
\hline $\begin{array}{l}\text { Exclusions (from } N=\mathbf{6 4 , 6 0 5} \text { parents ages } 21-60 \\
\text { with resident child): } \\
\text { - Weekend diaries }(\mathrm{N}=25,652) \\
\text { - Self-employed }(\mathrm{N}=14,057) \\
\text { - Rs working }<2 \text { hours on diary day }(\mathrm{N}=4,588) \\
\text { - Rs working neither at home nor in the workplace } \\
(\mathrm{N}=409) \\
\text { - Rs who report varying work hours }(\mathrm{N}=712) \\
\text { - Rs missing data }(\mathrm{N}=330) \\
\text { - Occupations incompatible with remote work }(\mathrm{N} \\
=4,735) \\
\text { - Unmatched Rs }(\mathrm{N}=1,603)\end{array}$ & $\begin{array}{l}\text { Exclusions (from } N=7,250 \text { leave module } \\
\text { parents ages } 21-60 \text { with resident child): } \\
\text { - Weekend diaries }(\mathrm{N}=3,625) \\
\text { - } \mathrm{R} \text { 's self-employed }(\mathrm{N}=50) \\
\text { - Rs working }<2 \text { hours on diary day }(\mathrm{N}=534) \\
\text { - Rs working neither at home nor in the workplace } \\
(\mathrm{N}=77) \\
\text { - Rs who report varying weekly work hours }(\mathrm{N}= \\
133) \\
\text { - Rs missing data }(\mathrm{N}=51) \\
\text { - Rs who do not telecommute for full days }(\mathrm{N}= \\
2,465)\end{array}$ & $\begin{array}{l}\text { Exclusions (from } N=\mathbf{N 8 , 5 2 2} \text { parents ages } 21-60 \\
\text { with resident child): } \\
\text { - Self-employed }(\mathrm{N}=10,780) \\
\text { - Rs who report varying weekly work hours }(\mathrm{N}= \\
\quad 4,066)\end{array}$ \\
\hline $\begin{array}{l}\text { Sample Features: All matched prime working- } \\
\text { age parents in employee jobs working } 2+\text { hours } \\
\text { during a M-F diary, working regular hours at home } \\
\text { or at work with complete data. }(\mathrm{N}=12,519) \text {. }\end{array}$ & $\begin{array}{l}\text { Sample Features: All prime working-age parents } \\
\text { in employee jobs working } 2+\text { hours during a M-F } \\
\text { diary, working regular hours at home or at work } \\
\text { with complete data who ever spend full days } \\
\text { working from home. }(\mathrm{N}=405) \text {. }\end{array}$ & $\begin{array}{l}\text { Sample Features: All prime working-age parents } \\
\text { in employee jobs working regular hours with a } \\
\text { child present. }(\mathrm{N}=83,676) \text {. }\end{array}$ \\
\hline $\begin{array}{l}\text { Outcomes: Childcare, housework, paid work, } \\
\text { work spells, work time with children present } \\
\text { Key coefficients: Gender, work location } \\
\text { Controls: Age, race/ethnicity, education, age of } \\
\text { youngest child, number of children, spousal } \\
\text { employment (all models); weekly work hours, } \\
\text { working part time, weekly earnings (except paid } \\
\text { work) }\end{array}$ & $\begin{array}{l}\text { Outcomes: Childcare, housework, paid work, } \\
\text { work spells, work time with children present } \\
\text { Key coefficients: Gender, work location } \\
\text { Controls: Frequency of telecommuting, spousal } \\
\text { employment }\end{array}$ & $\begin{array}{l}\text { Outcomes: Paid work, working part time for } \\
\text { family reasons } \\
\text { Key coefficients: Gender, remote work due to } \\
\text { pandemic } \\
\text { Controls: None }\end{array}$ \\
\hline
\end{tabular}

Note. $\mathrm{R}=$ respondent. ATUS $=$ American Time Use Survey. $\mathrm{CPS}=$ Current Population Survey. 
Table A2. P-Values for T-Tests of Differences between Diary Day Telecommuters and Workers in the Workplace for the Ever-Telecommuter Sample

\begin{tabular}{|c|c|c|c|c|}
\hline Variables & Men, unadjusted & Men, adjusted & Women, unadjusted & Women, adjusted \\
\hline Paid work last week (hours) & 0.653 & 0.513 & 0.087 & 0.666 \\
\hline Works part time & 0.246 & 0.675 & 0.298 & 0.975 \\
\hline Weekly earnings $(\log \$)$ & 0.226 & 0.548 & 0.95 & 0.467 \\
\hline Professional & 0.204 & 0.89 & 0.567 & 0.787 \\
\hline Manager & 0.688 & 0.446 & 0.349 & 0.866 \\
\hline Other job & 0.25 & 0.489 & 0.806 & 0.878 \\
\hline Age & 0.126 & 0.711 & 0.964 & 0.79 \\
\hline College degree & 0.902 & 0.725 & 0.81 & 0.81 \\
\hline Number of children & 0.104 & 0.0862 & 0.0989 & 0.11 \\
\hline Age of youngest child & 0.334 & 0.884 & 0.166 & 0.323 \\
\hline Black & 0.563 & 0.413 & 0.606 & 0.529 \\
\hline White & 0.703 & 0.689 & 0.391 & 0.142 \\
\hline Hispanic & 0.15 & 0.215 & 0.401 & 0.162 \\
\hline Married/cohabiting & 0.449 & 0.612 & 0.0729 & 0.118 \\
\hline Spouse works full time & 0.933 & 0.565 & 0.0273 & 0.0383 \\
\hline
\end{tabular}

Note: Data are from the 2017-18 American Time Use Survey ever-telecommuter sample, N = 405. P-values are from t-tests using residualized variables obtained from OLS regressions for each variable with the frequency of telecommuting as the sole predictor. 
Table A3. OLS Models of Time Use by Work Location and Gender for the Occupationally Matched Sample

\begin{tabular}{|c|c|c|c|c|c|}
\hline & Housework & Childcare & Paid work & Child presence d. work & Work spells \\
\hline \multicolumn{6}{|c|}{ Work location: (ref. = workplace only) } \\
\hline Mixed & $0.67(1.80)$ & $6.32 *(2.11)$ & $32.96 *(3.64)$ & $10.63 *(1.16)$ & $1.23 *(0.03)$ \\
\hline Home only & $15.50 *(3.01)$ & $29.53 *(3.53)$ & $-47.16 *(5.97)$ & $20.20 *(1.73)$ & $0.45 *(0.05)$ \\
\hline Female & $-967.28 *(434.13)$ & $1320.26 *(508.42)$ & $-383.10(872.49)$ & $-149.07(493.53)$ & $20.86 *(7.78)$ \\
\hline Age youngest child & $0.24(0.18)$ & $-5.09 *(0.21)$ & $0.90 *(0.36)$ & $0.06(0.11)$ & $0.01(0.00)$ \\
\hline Number of children & $2.24 *(0.77)$ & $1.76 *(0.90)$ & $0.31(1.56)$ & $0.67(0.50)$ & $-0.05 *(0.01)$ \\
\hline Paid work hours & $-0.33 *(0.08)$ & $-0.76 *(0.09)$ & & $0.03(0.05)$ & $-0.00 *(0.00)$ \\
\hline Part-time worker & $2.84(5.28)$ & $0.86(6.18)$ & & $1.68(3.39)$ & $-0.51 *(0.09)$ \\
\hline Age & $0.01(0.84)$ & $4.34 *(0.99)$ & $5.57 *(1.68)$ & $1.04(0.56)$ & $-0.00(0.02)$ \\
\hline $\mathrm{Age}^{2}$ & $0.01(0.01)$ & $-0.05 *(0.01)$ & $-0.07 *(0.02)$ & $-0.01 *(0.01)$ & $0.00(0.00)$ \\
\hline \multicolumn{6}{|c|}{ Spousal employment: (ref. = no spouse) } \\
\hline Spouse not employed fulltime & $-10.98 *(3.00)$ & $8.91 *(3.52)$ & $-1.48(5.97)$ & $1.25(2.03)$ & $0.21 *(0.05)$ \\
\hline Spouse works fulltime & $-2.33(3.01)$ & $21.43 *(3.53)$ & $-9.35(6.02)$ & $2.43(2.03)$ & $0.12 *(0.05)$ \\
\hline College degree & $0.43(1.64)$ & $4.59 *(1.92)$ & $-11.99 *(3.18)$ & $-0.16(1.09)$ & $-0.03(0.03)$ \\
\hline \multicolumn{6}{|c|}{ Race/ethnicity: (ref. = not Black or Hispanic) } \\
\hline Black & $-6.54 *(3.01)$ & $-9.44 *(3.52)$ & $10.23(6.00)$ & $0.32(1.92)$ & $0.04(0.05)$ \\
\hline Hispanic & $-6.53 *(2.52)$ & $-3.03(2.95)$ & $10.98 *(5.07)$ & $0.29(1.62)$ & $0.01(0.05)$ \\
\hline Weekly earnings $(\log \$)$ & $-6.30 *(1.43)$ & $2.85(1.68)$ & & $-0.20(0.92)$ & $-0.17 *(0.03)$ \\
\hline \multicolumn{6}{|l|}{ Female $\mathrm{x}$ work location } \\
\hline Mixed & $4.36(2.81)$ & $3.54(3.29)$ & $-4.15(5.64)$ & $5.17 *(1.78)$ & $-0.05(0.05)$ \\
\hline Home only & $8.38(4.29)$ & $-10.73 *(5.02)$ & $-17.03 *(8.58)$ & $5.27 *(2.54)$ & $0.10(0.08)$ \\
\hline Female $\mathrm{x}$ Age youngest child & $0.53 *(0.26)$ & $-3.67 *(0.31)$ & $2.60 *(0.53)$ & $-0.21(0.17)$ & $-0.02 *(0.00)$ \\
\hline Female $x$ Number of children & $5.84 *(1.20)$ & $-0.65(1.41)$ & $-3.15(2.44)$ & $-1.67 *(0.76)$ & $-0.02(0.02)$ \\
\hline Female x Work hours & $-0.77 *(0.14)$ & $0.12(0.16)$ & & $-0.02(0.09)$ & $0.00(0.00)$ \\
\hline Female x Part-time worker & $-2.99(6.16)$ & $14.35 *(7.22)$ & & $0.85(4.01)$ & $0.11(0.11)$ \\
\hline Female x Age & $-2.18(1.20)$ & $-2.60(1.41)$ & $-9.20 *(2.41)$ & $-0.51(0.78)$ & $0.02(0.02)$ \\
\hline Female $x$ Age $^{2}$ & $0.03 *(0.01)$ & $0.03(0.02)$ & $0.10 *(0.03)$ & $0.01(0.01)$ & $-0.00(0.00)$ \\
\hline \multicolumn{6}{|l|}{ Female x Spousal employment: } \\
\hline Spouse not employed fulltime & $14.34 *(3.98)$ & $-30.88 *(4.66)$ & $12.57(7.97)$ & $-0.29(2.60)$ & $-0.26 *(0.07)$ \\
\hline Spouse works fulltime & $13.45 *(3.58)$ & $-27.94 *(4.20)$ & $2.33(7.19)$ & $0.64(2.37)$ & $-0.19 *(0.06)$ \\
\hline Female x College degree & $0.93(2.43)$ & $-2.67(2.84)$ & $29.54 *(4.71)$ & $-0.19(1.61)$ & $0.00(0.04)$ \\
\hline \multicolumn{6}{|l|}{ Female $\mathrm{x}$ race/ethnicity: } \\
\hline Black & $-3.62(3.86)$ & $1.50(4.52)$ & $0.35(7.75)$ & $3.14(2.48)$ & $0.01(0.07)$ \\
\hline Hispanic & $5.36(3.63)$ & $-2.66(4.25)$ & $-18.28 *(7.32)$ & $1.93(2.25)$ & $-0.10(0.07)$ \\
\hline Female x Weekly earnings $(\log \$)$ & $-2.43(1.97)$ & $-1.48(2.31)$ & & $0.62(1.27)$ & $0.09 *(0.04)$ \\
\hline
\end{tabular}


Figure A1. Predicted Time Use Gender Gaps by Work Location and Couples' Work Arrangements

\section{A. Mother works part time}

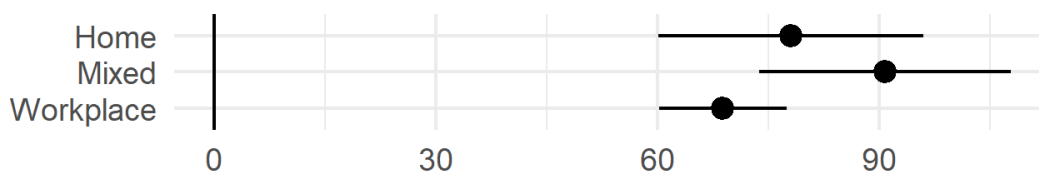

Childcare (minutes)
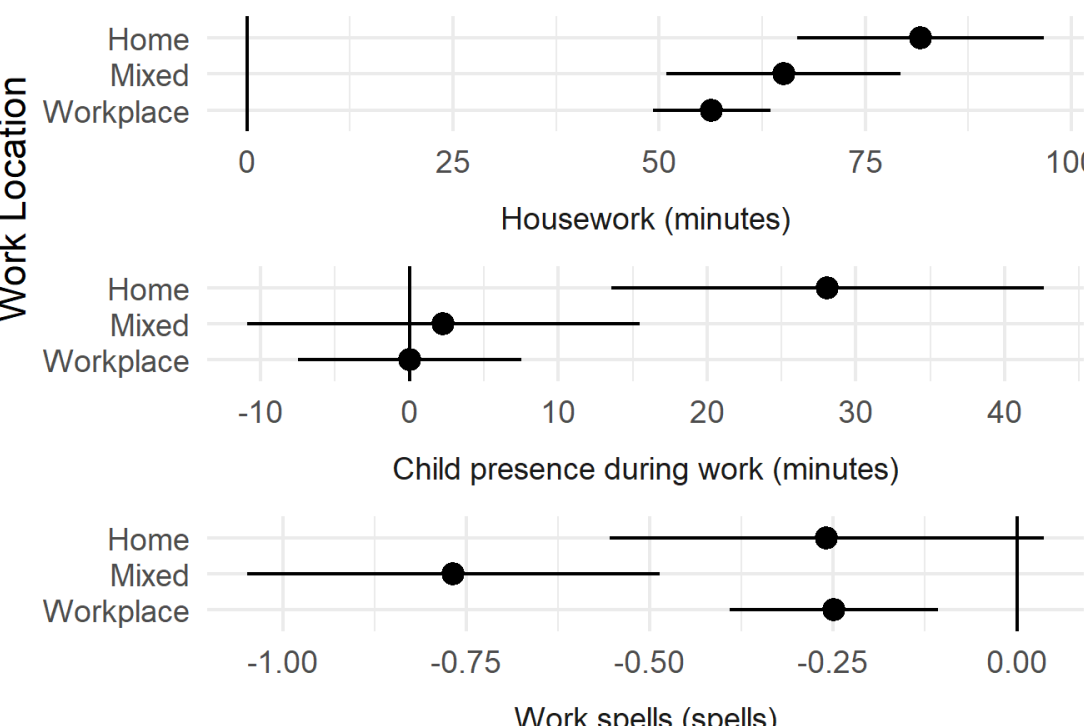

B. Both parents work full time

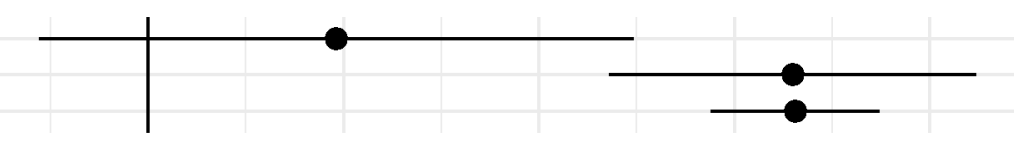

10

20

30

40

Childcare (minutes)

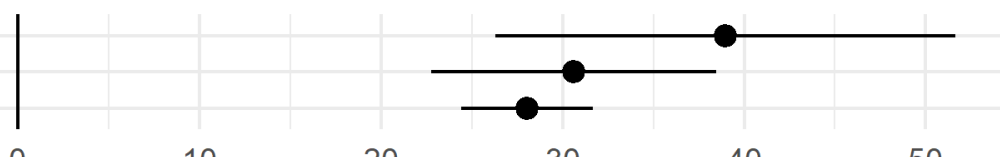

20

Housework (minutes)

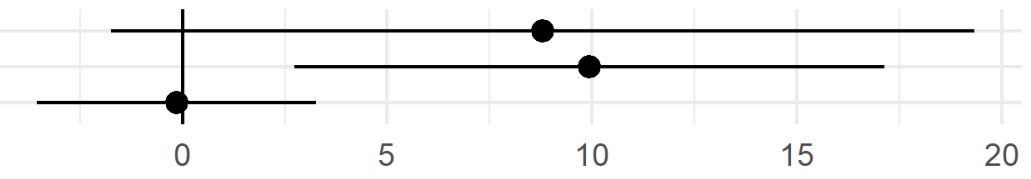

Child presence during work (minutes)

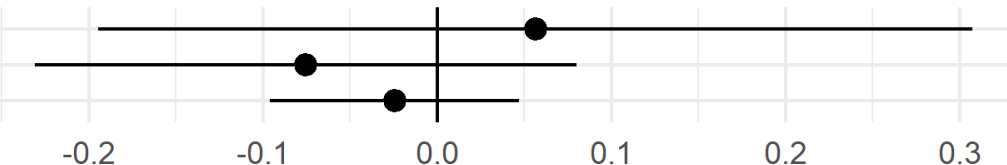

Work spells (spells)

Note: Data are from the 2003-2018 American Time Use Survey. Sample includes coupled parents in which either both parents work full time or mothers work part time and fathers full time. Observations are matched on occupation and estimates are adjusted for age, race/ethnicity, education, earnings, and number and age of children. We do not estimate models of paid work time because we already categorize respondents on the basis of gender gaps in work time (i.e., work arrangement) in this set of analysis, and partners' work arrangement may be a result of telecommuting. 